\title{
Optical and Photoelectrochemical Investigation of Mixed Photoactive Poly 2,2',5,2" ter-thiophene and Poly 2,2 bithiophene. Role of Intermixed Phases Created By the Co-electro-polymerization Process
}

\author{
Kasem K. Kasem ${ }^{1}$, Monica Schultz ${ }^{1}$, Sarah H. Osman ${ }^{1}$ \\ ${ }^{1}$ School of Sciences, Indiana University Kokomo, Kokomo, IN, USA \\ Correspondence: Kasem K. Kasem, School of Sciences, Indiana University Kokomo, Kokomo, IN, USA.
}

Received: September 22, 2019

Accepted: November 25, 2019 Online Published: November 26, 2019

doi:10.5539/ijc.v12n1p49

URL: https://doi.org/10.5539/ijc.v12n1p49

\begin{abstract}
Fluorine-doped tin oxide (FTO) electrodes modified with polymeric films of poly 2,2 bithiophene (PBth) and/or poly 2,2',5,2'-terthiophene (PTerth) were subjected to optical, photoelectrochemical (PEC), and electrochemical impedance spectroscopy (EIS) studies. Electropolymerization of mixed monomers containing bi-thiophene (Bth) and ter-thiophene (Terth) with different ratios resulted in the formation of intermixed phases. The recorded optical and PEC and EIS outcome data show that these intermixed polymer networks do not follow a monotonic relationship with the monomer ratios used to generate them. Optical studies indicate the formation of indirect and direct band gaps in the intermixed phases. Films generated in mixed monomers have greater energy-band tails than those generated from pure monomers. PEC studies indicated that these intermixed phases possess $p-p$ type hole accumulations, evident from the initial sharp rise in photocurrent. EIS results did not support linear relationship between the percent of Bth in monomer mixture and the dielectric-related properties such as barrier energy Wm, hopping frequency ( $\omega$ hopping), electrical conductivity $(\sigma)$, and density of state at Fermi level $\mathrm{N}\left(\mathrm{E}_{\mathrm{F}}\right)$.
\end{abstract}

Keywords: intermixe polymers, optical, photoelectrochemical, organic semiconductors

\section{Introduction}

Many $\pi$-conjugated conducting polymers can be photoactive. Several studies were conducted to decipher the reason(s) behind the photoactivties (Bard 1979, Grrett et al 1955), Holmes 1961, Oyama 1989, Causa et al 2016, Mohammed, et al 2008, Yen Wei et al 1991, Kolodziejczyk et al 2014). Factors such as the influence of chain length on energy gaps, orbital energies, ionization potential (IP), and electron affinity (EA) were taken into consideration. The electronic and structural properties of polythiophenes, ranging from an oligothiophene to infinite chain lengths have been studied. The possible involvement of dimer (2T) and hexamer (6T) in polymerization process has been reported (Oyama 1989). Such study also show that the larger the number of the units in polymer chain, the lower the energy gap between high occupied molecular orbitals (HOMO)/ lower unoccupied molecular orbitals (LUMO) HOMO and LUMO. The material is described as photoactive when the processes of charge generation that includes electron-hole $(\mathrm{e} / \mathrm{h})$ formation, separation, motilities are coordinated and photocurrent generation is observed.

Upon illumination with photons possessing energies $\geq$ the band gap of an organic polymer, electron-holes are generated. The fates of e/h separation and further transfer is determined by two factors: 1) the indirect changes in molecular arrangements that alter the donor/acceptor orientation and separation, and 2) the contribution of local environmental changes caused by disorder, microscopic field delocalization and energy gradients (Martina et al 2016). Previous studies suggested the possibility that two distinct pools of e/h pairs with different electronic couplings are generated directly after exciton dissociation: First, a loosely-bound e/h dissociates to free charges which leads to the observed decay in electron modulated differential absorption spectroscopy (EDA) signals. Secondly, strongly-bound electrons repeatedly recombine and can be observed in transit absorption (TA) spectroscopy (Mohammed, et al 2008).

Electropolymerization of mixed monomers containing two or three identical heterocyclic rings (e.g bithiophene and ter-thiophene), or di-functional heterocyclic rings can lead to formation of intermixed phases. These phases can affect long-range charge separation and the chance for delocalization into such intermixed network. Electrochemical polymerization of thiophene and 3-alkylthiophenes in the presence of a small amount of 2,2'-bithiophene or 2,2,:5'2"-terthiophene was performed (Yen Wei et al 1991). This study suggested that in the presence of bithiophene and ter-thiophene as additives, the number of nucleation sites of the polymers on the surface of the electrode is much greater, 
resulting in more uniform polymer films, and further it also suggested that no apparent structural difference between the polymers produced in the absence and in the presence of the additives. Electrochemical and optical properties of a conducting co-polymer composite film based on bithiophene and terthiophene were investigated (Kolodziejczyk et al 2014). This study concluded that some nano-walls can act as efficient nano-waveguides in the optical spectrum. In this type of single-mode strip waveguide, light travels through the polymer nano-wall material with negligible losses. Polymer films based on mixtures of terthiophene and bithiophene derivatives were tailored to suit the needs of optical devices such as solar cells, sensors and organic light emitting diodes (LED) (Kolodziejczyk et al 2019). The photoelectro-chemical properties of poly terthiophene films modified with 1-(3-methoxycarbonyl)-propyl-1-phenyl-(6,6) C61 (PCBM) has been investigated (Santos et al 2006).

Electropolymerization of polythiophene on stainless steel created a super-hydrophobic and superoleophilic coating that has been used in water /oil separation (de Leon A.C. et al 2019). Optical and photoelectro-chemical activities of pure and doped polybi-thiophene (PBth) were previously studied (Kasem et al 2016, Kasem et al 2017, Kasem et al 2018). These studies reported noticeable photo-activities of PBth. Photoelectrochemical properties of polyterthiophene (PTerth) films modified with a fullerene derivative was previous studied (Santos et al 2006), where PTerth is used to trap fullerene.

There is an increasing interest in tailoring mixed polymer that could generate the desired interfaces with optical and dielectical properties suitable for developing sensors and solar cells. In the present work, we studied the electro-polymerization of mixed monomers containing bi-thiophene (Bth) and ter-thiophene (Terth), to determine how the formation of intermixed phases of the produced polymers' mix can affect optical, dielectric properties, and the photoelectrochemical outcome of these mixed polymer networks.

\section{Experimental}

\subsection{Reagents}

The monomers 2,2'-bithiophene (BTh), and 2,2',5,2"'-Terthiophene (Terth) (Aldrich) were used to prepare their corresponding polymers. All of the chemicals used were of analytical grade. Unless otherwise stated, all of the electrolytes were prepared using deionized (DI) water.

\subsection{Preparations}

The polymers were prepared using cyclic voltammetry (CV) by repetitive cycling of the substrate electrode (FTO) potential between -0.1 and $0.2 \mathrm{~V} \mathrm{vs} \mathrm{Ag} / \mathrm{AgCl}$ in acetonitrile solution containing total $10 \mathrm{mM}$ of the monomer or the mixed monomers with different ratios (Table 1), and $0.5 \mathrm{M} \mathrm{LiClO}_{4}$.

\subsection{Instrumentation}

A conventional three-electrode cell consisting of a $\mathrm{Pt}$ wire as a counter electrode, an $\mathrm{Ag} / \mathrm{AgCl}$ reference electrode, and FTO with surface area $2.0 \mathrm{~cm}^{2}$ as a working electrode was used for electrochemical studies. Photoelectrochemical studies on the thin solid films were performed on the experimental setup as described in previous work (Kasem K. etal 2017). Optical parameters were calculated based on the steady state reflectance spectra, measured by a Shimadzu UV-2101PC spectrophotometer. Irradiation was performed with a solar simulator 300-watt xenon lamp with an IR filter. All measurements were performed at $298 \mathrm{~K}$. A Solartron 2101A was used for EIS studies. A BAS 100W electrochemical analyzer (Bioanalytical Co.) was used to perform the electrochemical studies.
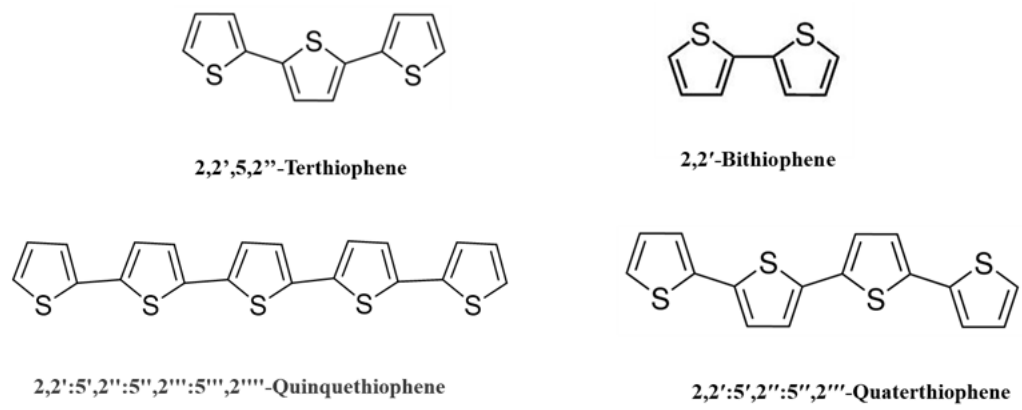

Figure 1 Structural formulas for the monomers and their possible dimers. 


\section{Results and Discussion}

\subsection{Electrochemical Polymerization}

FTO substrates were subject of potential cycling in nonaqueous electrolytes containing the monomer/s mixtures. We labeled polymers generated from the following: 1) pure BTh, as PC1, 2) $7.5 \mathrm{mM} \mathrm{BTh} / 0.25 \mathrm{mM}$ Terth as PC2 3) $5.0 \mathrm{mM}$ PBTh/5 mM Terth as PC3, 4- $2.5 \mathrm{mM} \mathrm{BTh/7.5} \mathrm{Terth} \mathrm{as} \mathrm{PC4,} \mathrm{and} \mathrm{5-} 10 \mathrm{mM}$ Terth as PC5. The CV generated during this process are recorded and displayed in Figure 2. The set-oxidation potential of pure Terth (PC5) (Figure 2C) is $0.75 \mathrm{~V}$ vs $\mathrm{Ag} / \mathrm{AgCl}$. The corresponding ionization potential (IP) or $\mathrm{HOMO}$ is at $5.35 \mathrm{eV}$ in a vacuum scale. While for Pure BTh (PC1), the set-oxidation potential is $1.22 \mathrm{~V}$ vs $\mathrm{Ag} / \mathrm{AgCl}$ (Figure $2 \mathrm{~A}$ ), and the IP value is $5.82 \mathrm{eV}$. In Figure $2 \mathrm{~B}$, where both monomers were mixed in equi molar ratio $(5 \mathrm{mM})(\mathrm{PC} 3)$, there are two oxidation peaks at 1.45 and $1.2 \mathrm{~V}$ vs $\mathrm{Ag} / \mathrm{AgCl}$. These two oxidation peaks are related to oxidation of pure BTh and Terth respectively to form radical cations that initiate the polymerization process to form polymers and possible oligomers. The changes in oxidation peak potentials in the successive scans can be attributed to the electrooxidation after the first scan took place on the partially or fully covered FTO surface, and also due to formation of oligomers that require different oxidation potentials for further polymerization. All of the formed films were electrochromic. Electro polymerizations from monomer mixtures containing $2.5 \mathrm{mM} \mathrm{BTh}+7.5 \mathrm{mM}$ Terth (PC4), and 7.5 mM BTh $+2.5 \mathrm{mM}$ Terth (PC2), were also performed. The resulting CV (not shown) were similar to that in Figure 2B. The electrodeposition process was controlled to achieve approximately $1.0 \mu \mathrm{m}$ film thickness.

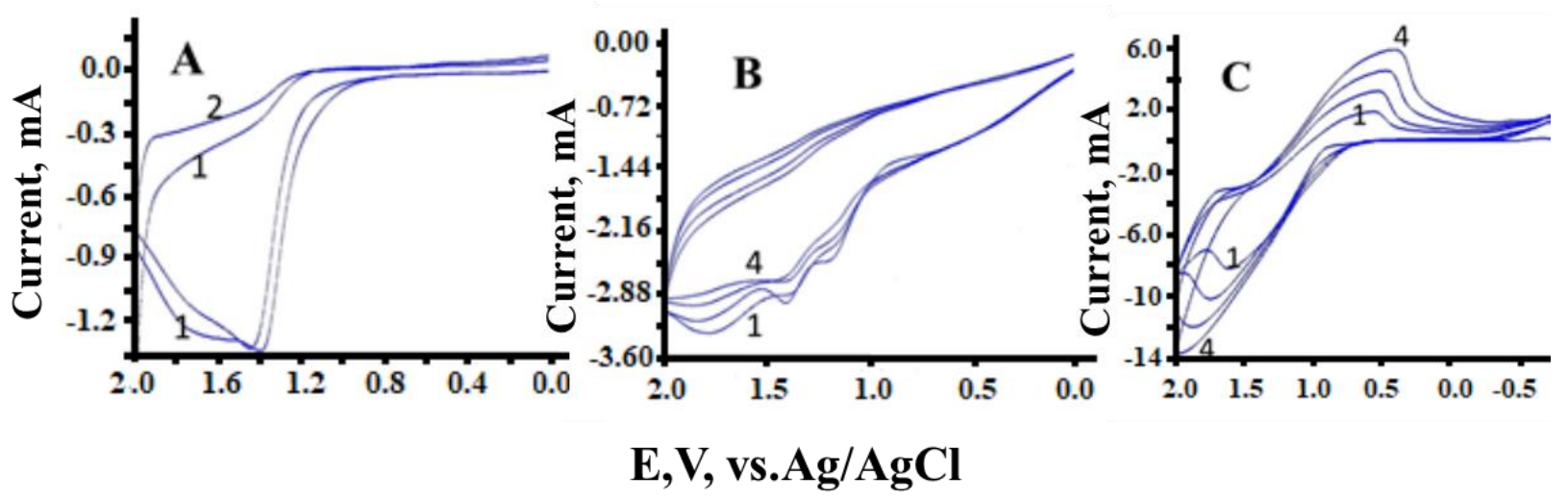

Figure 2. $\mathrm{CV}$ for the oxidative electropolymerization on $\mathrm{FTO}$ in acetonitrile containing $\mathrm{LiClO}_{4}$ and the $\mathrm{X} \mathrm{mM}$ of monomers, A) $10 \mathrm{mM}$ of BTh (PC1), B) $5 \mathrm{mM}$ BTh and $5 \mathrm{mM}$ Terth (PC3), and C) $10 \mathrm{mM}$ Terth (PC5). Scan rate was $0.10 \mathrm{~V} / \mathrm{s}$. Scan numbers are labeled on the Figures

\subsection{Optical Studies}

Absorption spectra and optical conductivity $\left(\sigma_{\mathrm{opt}}\right)$ of thin films of intermixed phases of PBTh and PTerth were investigated. The results are displayed in Figures 3 and 4.

\subsubsection{Optical Band Gap Studies}

The absorption spectra of films generated from monomer mixtures identified in Table 1 are displayed in Figure 3. The presence of random multi-absorption peaks for films generated from mixed monomer electrolytes can be explained on the basis of the existence of mixed multiphase. The absorption $\lambda_{\max }$ for these phases does not reflect a monotonic relations to the monomer mixture concentrations. Films generated from pure Terth show two absorption peaks (Table 1 and Figure 3), one at $2.8 \mathrm{eV}$ and the other is at $3.3 \mathrm{eV}$. Such behavior was not observed with films generated from pure BTh. It is possible that Terth makes more stable oligomers than Bth. This also explain the presence of multi absorption peaks with films made from mixed monomers (PC1-PC4).

The treatment of the absorption data from Figure 3 for all studied assemblies were listed as described in previous study (Tauc 1968). The plots photon energy (hv) vs $\alpha 1 \frac{1}{2}$, and $(\alpha * h v)^{2}$ respectively generated (Figures are not shown), and data about indirect or direct band gaps were obtained and listed in Table 1 . The quantities listed in Table 1 do not reflect any linear or monotonic relationship between the film band gap and the mixed phase film structure. By plotting $\log (\alpha)$ vs photon energy, we were able to calculate absorption band tails attributed to the energy band tail or Urbach energy (Urbach 1953). The quantities of Urbach energy listed in Table 1, show that films generated in mixed monomers have greater energy-band tails than those generated in pure monomer. 


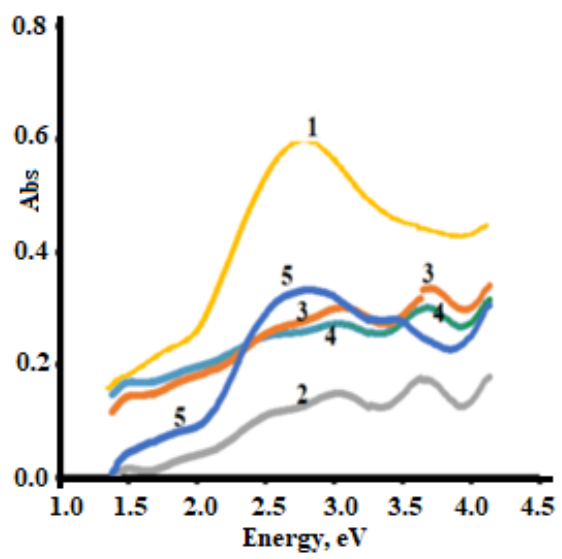

Figure 3. Absorption spectra of $1.0 \mu \mathrm{m}$ films made from: 1) pure BTh (PC1), 2) $7.5 \mathrm{mM} \mathrm{BTh} / 0.25 \mathrm{mM}$ Terth (PC2), 3) 5.0 mM PBTh/5 mM Terth (PC3), 4) $2.5 \mathrm{mM} \mathrm{BTh} / 7.5$ Terth (PC4), and 5) $10 \mathrm{mM}$ Terth (PC5)

Table 1. Optical band gap for the studied films prepared from listed monomer concentrations

\begin{tabular}{cccccc}
\hline \multicolumn{2}{c}{$\begin{array}{c}\text { mmole of } \\
\text { BTh }+ \text { Ter }\end{array}$} & $\begin{array}{c}\approx \text { band gap } \\
\text { at } \lambda \text { max, eV }\end{array}$ & $\begin{array}{c}\text { Direct band } \\
\text { gap }(\mathrm{eV})\end{array}$ & $\begin{array}{c}\text { Indirect band } \\
\text { gap (eV) }\end{array}$ & $\begin{array}{c}\text { Urbach } \\
\text { energy (eV) }\end{array}$ \\
\hline $10+0$ & (PC1) & 2.6 & 2.0 & 1.6 & 0.518 \\
$7.5+2.5$ & (PC2) & $2.4,3.1,3.7$ & 2.45 & $1.75,2.25$ & 0.901 \\
$5.0+5.0$ & (PC3) & $2.5,3.1,3.7$ & 2.25 & 1.72 & 1.378 \\
$2.5+7.5$ & (PC4) & $2.6,3.1,3.7$ & 2.25 & 1.7 & 1.964 \\
$0+10$ & (PC5) & $2.8,3.3$ & 2.25 & 1.7 & 0.455 \\
\hline
\end{tabular}

3.2.2 Optical conductivity $\sigma_{\text {opt }}$ and Electrical Conductivity $\sigma_{\text {ele }}$

Both $\sigma_{\mathrm{opt}}$ and $\sigma_{\mathrm{ele}}$ were calculated using the following formulas (Sharma et al 2007, Sabari et al 2009):

$$
\begin{aligned}
& \sigma_{o p t}=\frac{\alpha n c}{4 \Pi} \\
& \text { and } \sigma_{\text {ele }}=\frac{2 \lambda \sigma_{o p t}}{\alpha}
\end{aligned}
$$

Figure 4 clearly shows that for the polymers generated as described in Table 1,1$)$ the $\sigma_{\mathrm{opt}}$ increases with increasing photon energy up to $2.5 \mathrm{eV}$ after which starts to decrease for PC1 and PC5; 2) for PC2, PC3, and PC4 the $\sigma_{\text {opt }}$ increase steadily with fluctuation trend up to $\sim 3.2 \mathrm{eV}$, and 3) $\sigma_{\text {opt }}$ is low at longer wave lengths (Photon energy $<2.0 \mathrm{eV}$. At a photon energy greater than $3.5 \mathrm{eV}$ the optical conductivity increases again. Such behavior can be attributed to the network structure of these mixed phases that facilitate an additional charge transfer (Sharma P. et al 2007). Figures 4B and $4 \mathrm{C}$ indicate that optical conductivity is much greater than the electrical conductivity. Such behavior is explained on the basis of the Drude model (Drude 1900). In the absence of alternating frequency, optical conductivity can be considered as electrical conductivity.

\subsection{Photoelectrochemical Behavior of Films of Intermixed Phases of PBTh and PTerth}

The electrochemical studies on FTO/modified with polymers PC1, PC2, PC3, PC4, and PC5 were achieved by cycling the potential of FTO modified with each of these assemblies in acetate, citrate, and phosphate electrolytes $(\mathrm{pH}=7.6)$. The studies were performed in the dark and under illumination, with a scan rate of $0.10 \mathrm{~V} / \mathrm{s}$, between, unless otherwise stated, -1.0 to $1.0 \mathrm{~V}$ vs $\mathrm{Ag} / \mathrm{AgCl}$. The chronoamperometric studies were also performed at $-0.50 \mathrm{~V}$ vs $\mathrm{Ag} / \mathrm{AgCl}$. The results are displayed in Figures 5-8. 

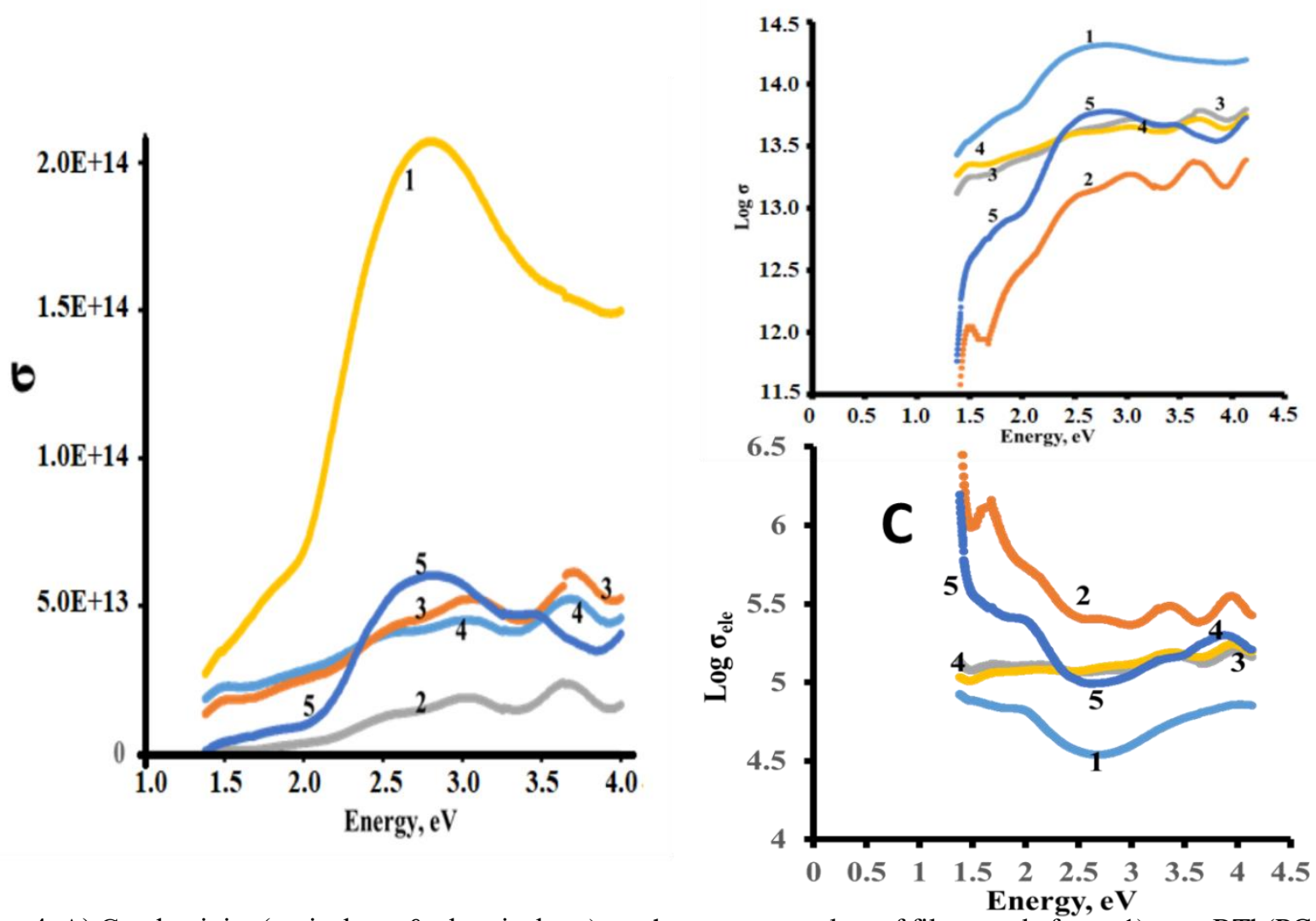

Figure 4. A) Conductivity (optical $\sigma_{\text {opt }} \&$ electrical $\sigma_{\text {ele }}$ ) vs photon energy plots of films made from: 1) pure BTh(PC1), 2) $7.5 \mathrm{mM} \mathrm{BTh} / 0.25 \mathrm{mM}$ Terth (PC2), 3) $5.0 \mathrm{mM} \mathrm{PBTh} / 5 \mathrm{mMTerth}(\mathrm{PC} 3), 4) 2.5 \mathrm{mM} \mathrm{BTh} / 7.5$ Terth (PC4), and 5) $10 \mathrm{mM}$ Terth (PC5), A) $\sigma_{\text {opt }}$, B) $\log \sigma_{\text {opt }}$ and C) $\log \sigma_{\text {ele }}$ vs photon energy

Figure 5 displays the $\mathrm{CV}$ of these films in citrate electrolyte in the dark and under illumination. It can be noticed that films of PC1 (or PBTh) generate more photocurrent in the potential range $0.0-1.0 \mathrm{~V} \mathrm{vs} \mathrm{Ag} / \mathrm{AgCl}$. The observed greater current found under illumination than in dark, indicates that films made in pure Bth or (PC1) (Figure 5A) offered great charge separation and much less charge recombination. As the percentage of Bth monomer decreased and percentage of Terth increases in the polymerization mixture (Figure 5B, C and D), the difference between photocurrent and dark current decreases. The smallest difference between photo and dark current is obtained with films made in pure Terth (Figure 5E). As the photocurrent is a direct result of charge separation and transfer, we suggest that films made in mixed monomer solutions offer less charge separation and allow more charge recombination. 

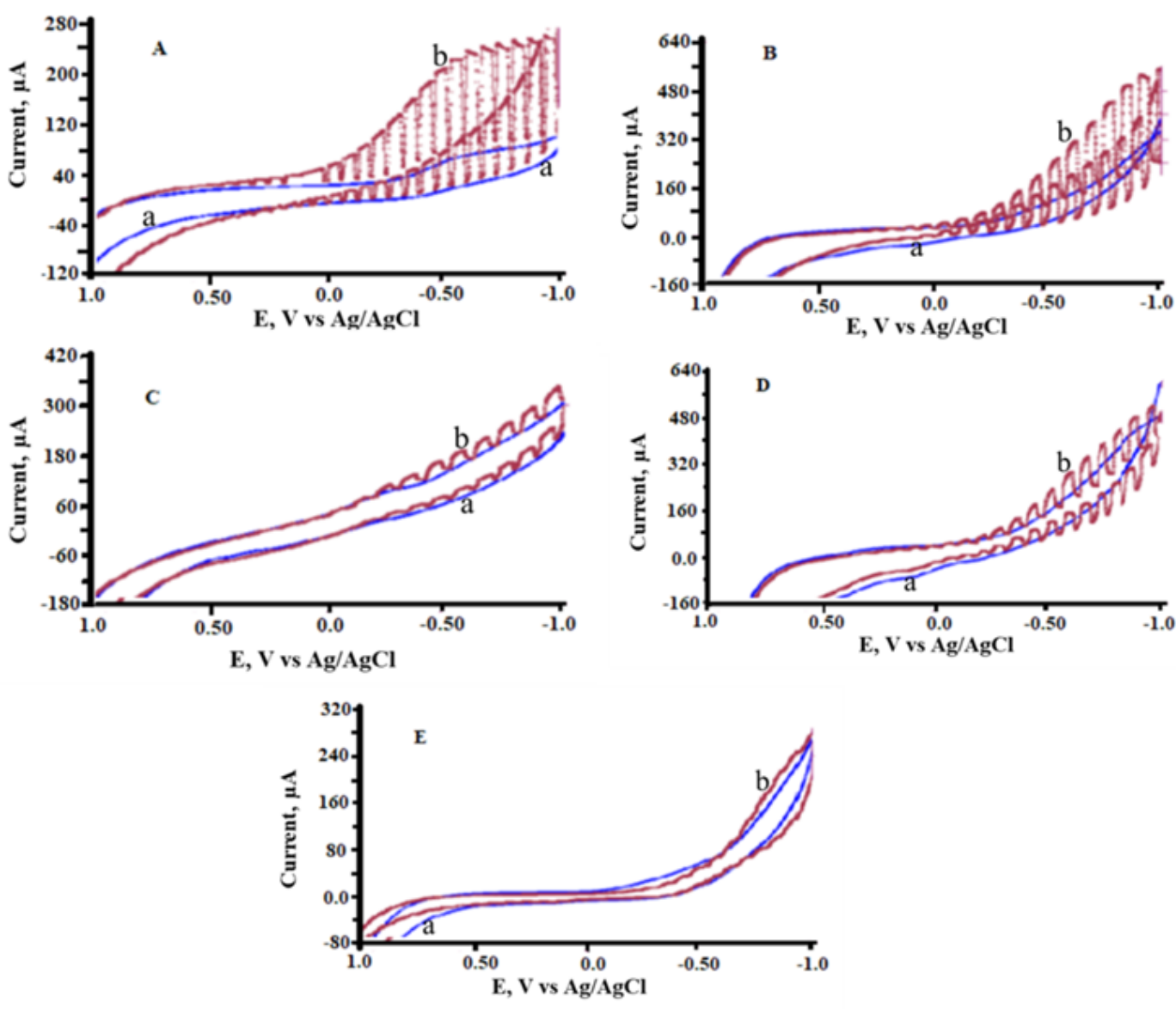

Figure 5. CV for FTO modified with films made from: A) pure BTh(PC1), B) $7.5 \mathrm{mM} \mathrm{BTh} / 0.25 \mathrm{mM}$ Terth(PC2), C) 5.0 $\mathrm{mM}$ PBTh/5 mmTerth(PC3), D) $2.5 \mathrm{~mm}$ BTh/7.5 Terth(PC4), and E) $10 \mathrm{~mm}$ Terth (PC5) in 0.2M citrate electrolyte $\mathrm{pH}$ 7.6. a) in dark, and b) under illumination

\subsubsection{Photocurrent Transients}

The photocurrent-time response was studied by performing chronoaperometric measurements in acetates (Figure 6a), citrate (Figure 6b) and in phosphate electrolytes (Figure 6c) of films generated from PC1, PC2, PC3, PC4, and PC5 at $-0.500 \mathrm{~V} \mathrm{Vs} \mathrm{Ag/AgCl}$, under dark and long term illumination. The choice of $-0.50 \mathrm{~V}$ is based on the results obtained in Figure 5, where a large difference between photocurrent and dark current is reported. The behavior for films PC1 (or PBTh) (Figure 6A), PC3 (mixed polymer structure) (Figure 6B), and PC5 (PTerth) (Figure 6C) show an instant rise in the photocurrent upon illumination in all of the studied cases in all electrolytes. However films generated from pure monomers PC1 (Figure 6A) and PC5 (Figure 6C) show a reproducible current spike appearing at the beginning of illumination time and then droping with different rate, followed by slow rise in photocurrent. These current spikes varied based on the used electrolyte. The presence of current spikes is an indication of hole accumulation (Brennan et al 2015). The slow rise in photocurrent was attributed to the short lifetime of photo-excited states and possible lattice relaxation at the surface (Reemts et al 2007). Such phenomena were not observed in PC3 (Figure 6B). The magnitudes of the photocurrent generated in each electrolyte for all studied assemblies are recorded in Figure 7. This figure indicates clearly the lack of a monotonic linear relationship between the percentages of Bth in the monomer mixtures used in the elctropolymerization to generate intermixed phases. However this Figure shows that in both phosphate and acetate electrolytes, a maximum photocurrent is generated by PC2 and PC4. 


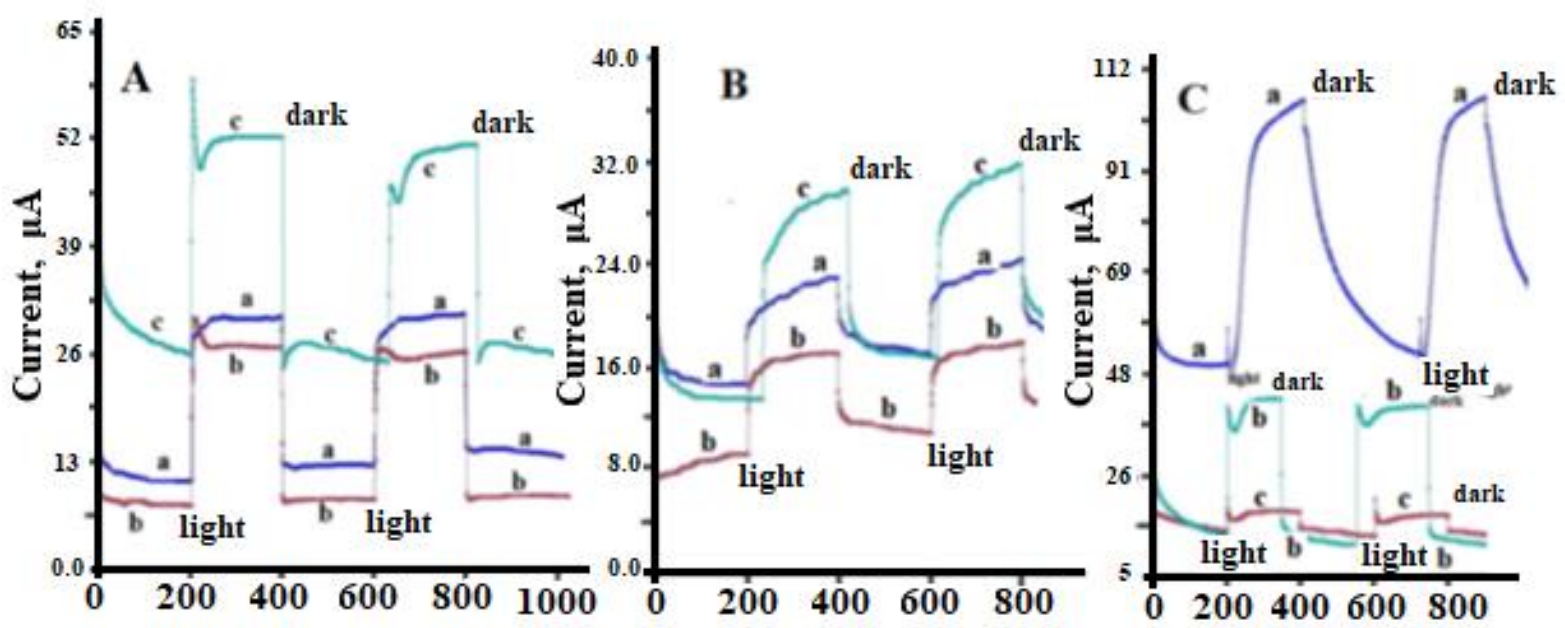

Figure 6. Chronoamperometric studies at $-0.50 \mathrm{~V}$ vs $\mathrm{Ag} / \mathrm{AgCl}$ Photocurrent transient plot for FTO modified with films made from: A) pure BTh PC1, B) $5.0 \mathrm{mM} \mathrm{PBTh} / 5 \mathrm{mMTerth}$ (PC3), and C) 10 mMTerth (PC5). In $0.2 \mathrm{M}$ electrolyte (pH $=7.6$ ), a) acetate electrolyte, b) citrate electrolyte, and c) Phosphate electrolyte

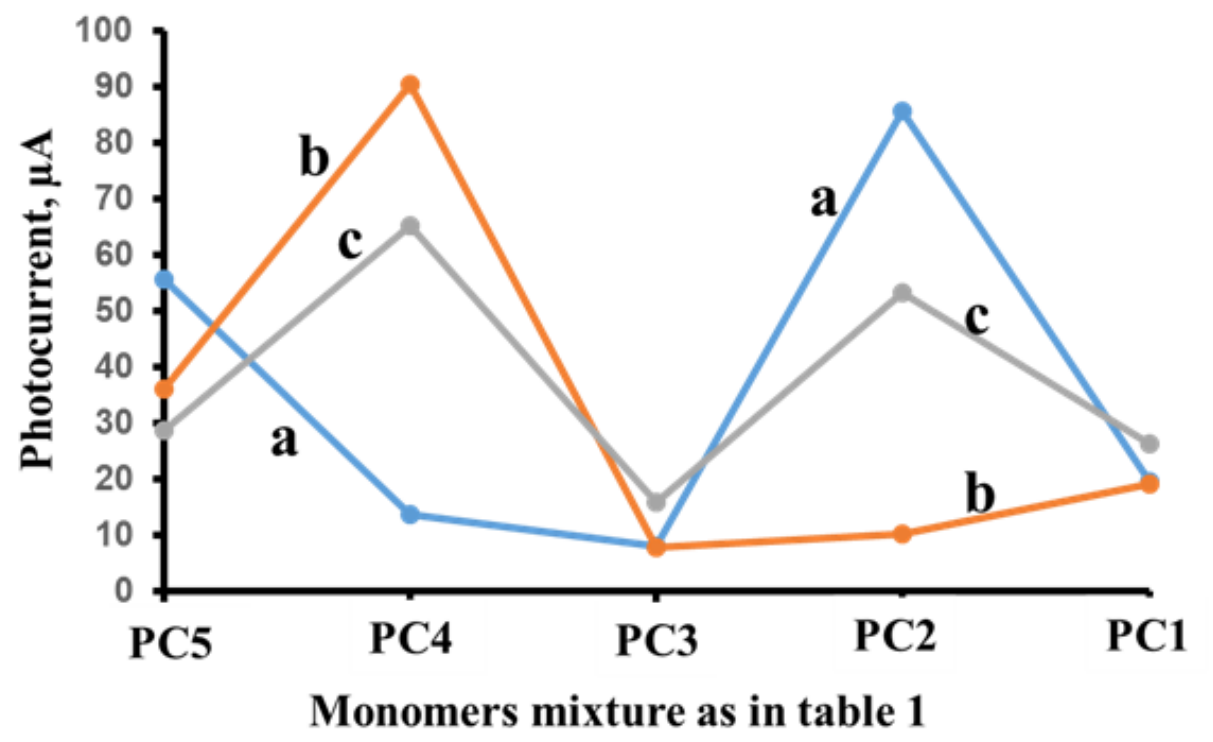

Figure 7. Photocurrent transient at $-0.5 \mathrm{~V}$ vs $\mathrm{Ag} / \mathrm{AgCl}$ for $\mathrm{FTO}$ modified with films made from varying percentage of Bth and Terth monomers in $0.2 \mathrm{M}(\mathrm{pH}=7.6)$ electrolytes, a) acetate, b) citrate, and c) phosphate

\subsubsection{Hole Accumulation Phenomena}

The observed photocurrent spikes in Figure 6, were explained on a basis of the existence of hole accumulation in the mixed phases of the organic polymers. These organic polymers have a p-type nature. When a p-p type heterojunction is created, possible hole accumulation can take place. This was evident from the appearance of these sharp rises in the photocurrent. Quantitative analysis of the concentration of these hole accumulations and their effect of the transient current time constant was carried out. Figure 8 displays an exploded view of photocurrent-time curves for PC2, PC4, and PC5 in citrate electrolyte.

The concentration of accumulated holes were calculated (Table 2) by integrating the area under each spike (Figure 7) with consideration of the charge density and photochemical equivalence law.

Furthermore considering the following equation (Spadavecchia et al 2013). 


$$
R=e^{-\frac{t}{\tau}}
$$

where $t$, time, $\tau$ is transient time constant and $R=\left(I_{t}-I_{s t}\right) /\left(I_{i n}-I_{s t}\right)$, as $I_{t}$ is current at time $t, I_{\text {in }}$ is immediate photocurrent, and $\mathrm{I}_{\mathrm{st}}$ is the stationary value of photocurrent (steady current).

The plot of $\log \mathrm{R}$ vs time, generate a straight line with slope $=1 / \tau$. The reciprocal of the slope determines the value of $\tau$, in seconds.

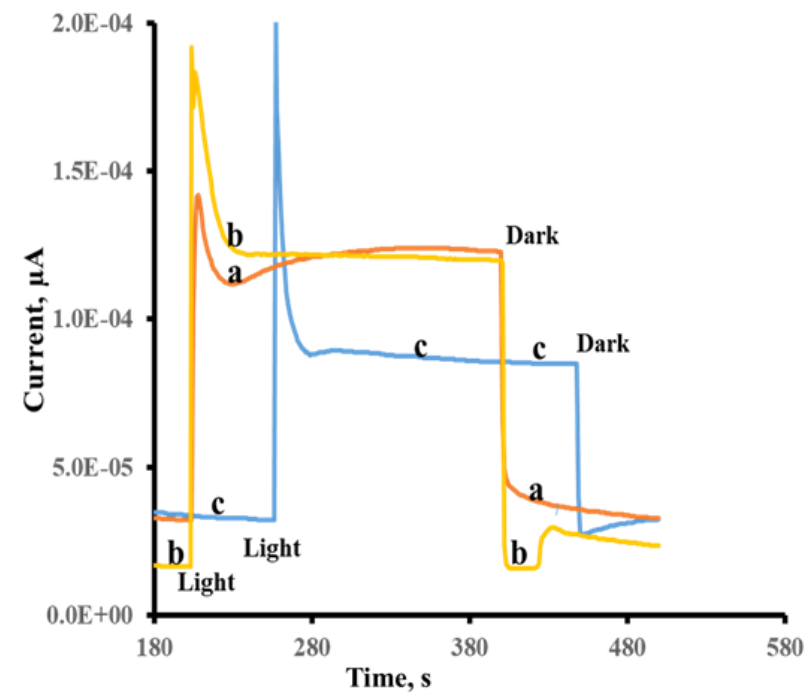

Figure 8. Photocurrent transient record for a) PC4, b) PC2, and c) PC5 in citrate electrolyte

The data listed in Table 2 indicate that the greatest hole accumulation concentration is reported with PC2 in citrate electrolyte. The fact that the transient current constant is longer (> 1 second) reflects slow electron-hole recombination and enhanced charge separation and charge transfer. Table 2 also shows that, no relationship between the concentration of Bth in the monomer mixture and either hole concentration (charge, mole) or transient time constant exists in any of the used electrolytes. This may be attributed to the uncontrollable conditions to generate consistent solid film structures. Oxidative electropolymerization of BTh, and Terth or their mixtures resulted in the formation of thin films. These films consist of intermixed phases that can be pure poly bi-thiophene (PBTh), poly terthiophene (PTerth) or insoluble oligomers with basic units of quinquethiophene or qutrathiophene (Figure 1). As organic semiconductors polythiophene are considered to be $p$-type. These intermixed phases are likely to generate $p$-p iso-type heterojunction interfaces with staggered band alignments. In such alignments, the phase with a lower Fermi level undergoes hole depletion, while that with a higher Fermi level undergoes hole accumulation. The final outcome can be seen in monitoring photocurrent-time curves. The structures of these intermixed phases, their orientations, and possible band alignments can result in generation of many assemblies. Each of these assemblies has an environment for charge trapping, separation, and transfer. This may explain the nonlinear outcomes listed in Table 2.

Table 2. Hole accumulation concentration and photocurrent transient time constants $\tau$, s, generated by intermixed phases prepared from the mixtures of BTh and Terth monomers

\begin{tabular}{cccccccc}
\hline \multirow{2}{*}{$\begin{array}{c}\text { BTh }+ \text { Ter } \\
(\text { mmole })\end{array}$} & $\begin{array}{c}c \\
\text { Charge } \\
(\text { mole })\end{array}$ & $\tau(\mathrm{s})$ & $\begin{array}{c}\text { Charge } \\
(\text { mole })\end{array}$ & $\tau(\mathrm{s})$ & $\begin{array}{c}\text { Charge } \\
(\text { mole })\end{array}$ & $\tau(\mathrm{s})$ \\
\hline $10.0+0$ & $(\mathrm{PC} 1)$ & & & $5.60 \times 10^{-10}$ & 7.067 & $7.81 \times 10^{-10}$ & 3.343 \\
$7.5+2.5$ & $(\mathrm{PC} 2)$ & $1.65 \times 10^{-8}$ & 4.773 & $1.02 \times 10^{-8}$ & 7.72 & $8.0 \times 10^{-}$ & 3.812 \\
$5.0+5.0$ & $(\mathrm{PC} 3)$ & & & & & & \\
$2.5+7.5$ & (PC4) & $8.17 \times 10^{-1}$ & 8.415 & $2.6 \times 10^{-9}$ & 3.717 & $3.8 \times 10^{-9}$ & 2.796 \\
$0+10.0$ & (PC5) & $2.36 \times 10^{-10}$ & 1,485 & & & $1.0 \times 10^{-9}$ & 3.61 \\
\hline
\end{tabular}




\subsubsection{Electrochemical Impedance Spectroscopy}

Impedance spectra of the studied assemblies were measured between $10^{5}-10^{-2} \mathrm{~Hz}$ in a three-electrode cell containing acetate, citrate, or phosphate electrolytes $(\mathrm{pH}=7.6)$. Impedance complexes (Nyquist plot) generated in the dark and under illumination from assemblies PC1, PC2, PC3, PC4, and PC5 on FTO substrate are displayed in Figure 9. This Figure shows only kinetic control at all frequencies. The dielectric behavior of the generated assemblies were explored at $25{ }^{\circ} \mathrm{C}$. This being achieved by further treatment of EIS data for each of the studied assemblies. We calculated AC conductivities $\left(\sigma_{\mathrm{ac}}\right)$ of these assemblies in phosphate buffer using the following equation (Joshia et al 2017):

$$
\sigma_{a c}=\frac{L}{a} * \frac{Z^{\prime}}{Z^{2}+Z^{\prime 2}}
$$

where $\mathrm{L}$ is the film thickness, and a, is the electrode surface area $\left(2 \mathrm{~cm}^{2}\right)$

The relation between $\sigma_{\mathrm{ac}}$ and DC conductivity $\left(\sigma_{\mathrm{dc}}\right)$, is illustrated in the following universal dynamic response (UDR) formula or Jonscher's power law (Jonscher. A.K 1977).

$$
\sigma_{\mathrm{ac}}=\sigma_{\mathrm{dc}}+\mathrm{A} \omega^{\mathrm{s}}
$$

where $\mathrm{A}$ is the strength of polarizability, $\mathrm{s}$ is the temperature-dependent parameter which can be determined from the plot of $\log \sigma_{\mathrm{ac}} \mathrm{vs} \log \omega$.

$$
\log \sigma_{\mathrm{ac}}=\log \sigma_{\mathrm{dc}}+\log \mathrm{A}+\mathrm{s} \log \omega
$$

Figure 10 displays a Nyquest plot, a Bodes plot, and a $\log \sigma_{\mathrm{ac}}$ vs $\log \omega$ plot for PC 3 in phosphate electrolyte at $-0.500 \mathrm{~V}$ vs $\mathrm{Ag} / \mathrm{AgCl}$. Figure $9 \mathrm{C}$ shows that PC3 exhibits sublinear behavior at lower frequencies. Similar treatments were carried up to determine the slope $\mathrm{s}$ in the power law. Hopping frequency $(\omega)$ and relaxation time $(\mathrm{T}, \mathrm{s})$ were determined for all studied assemblies (Figures are not shown). The results are summarized in Table 3. The exponent, s, in the power law is important in the determination of the potential barrier separating defect centers in the passes of charge carriers $(\mathrm{Wm})$.

$\mathrm{W}_{\mathrm{m}}$ can be calculated from the following relationship (Funke K. 1993):

$$
W_{m}=\frac{6 k_{B} T}{1-s}
$$

The values of $\mathrm{s}$ must be $\leq 1$, to generate positive value of $\mathrm{Wm}$, according to Equation 7 . Table 3, lists the exponent (s), barrier energy $\left(\mathrm{W}_{\mathrm{m}}\right)$, hopping frequency ( $\omega$ hopping), minimum hopping distance $\left(\mathrm{R}_{\min }\right)$ and density of state at Fermi level $\mathrm{N}(\mathrm{EF})$ at high frequency. No tangible changes in the listed $\mathrm{s}, \mathrm{W}_{\mathrm{m}}, \omega$ hopping, or $\mathrm{R}$ occurred upon illumination. However, density of states are lowered upon illumination. s was considered as a function of entropy (Jonscher. 1977), the lower the value of $\mathrm{s}$, the greater the entropy or the disorder of molecules or segments in the interface between different microstructure (heterogeneity) of this interface. The exponent $\mathrm{s}$ is then a function of movement of the segments. Decreasing s upon illumination indications of increasing entropy. Illumination created excited states and

\begin{tabular}{|c|c|c|c|c|c|c|c|c|c|c|}
\hline \multirow[t]{2}{*}{ Phase } & \multicolumn{5}{|c|}{ Dark } & \multicolumn{5}{|c|}{ Light } \\
\hline & $\mathrm{s}$ & $\begin{array}{c}\mathrm{W}_{\mathrm{m}} \\
(\mathrm{eV})\end{array}$ & $\mathrm{N}\left(\mathrm{E}_{\mathrm{F}}\right)$ & $\begin{array}{c}\omega_{\text {hopp }} \\
(\mathrm{KHz})\end{array}$ & $\begin{array}{c}\mathrm{R}_{\min }, \\
\mathrm{nm}\end{array}$ & $\mathrm{s}$ & $\begin{array}{c}\mathrm{W}_{\mathrm{m}} \\
(\mathrm{eV})\end{array}$ & $\mathrm{N}\left(\mathrm{E}_{\mathrm{F}}\right)$ & $\begin{array}{c}\omega_{\text {hopp }} \\
(\mathrm{KHz})\end{array}$ & $\begin{array}{l}\mathrm{R}_{\text {min }} \\
(\mathrm{nm})\end{array}$ \\
\hline $\mathrm{PC} 1$ & 0.750 & 0.613 & $2.52 \times 10^{20}$ & 0.631 & 1.4 & 0.731 & 0.570 & $2.21 \times 10^{20}$ & 0.631 & 1.5 \\
\hline PC2 & 0.287 & 0.215 & $2.97 \times 10^{18}$ & 15.92 & 10 & 0.263 & 0.208 & $1.67 \times 10^{18}$ & 15.85 & 10.7 \\
\hline PC3 & 0.359 & 0.239 & $1.13 \times 10^{19}$ & 5.011 & 5.4 & 0.336 & 0.231 & $1.10 \times 10^{19}$ & 2.512 & 5.5 \\
\hline PC4 & 1.005 & & $\ldots$ & 0.251 & & 0.843 & 0.976 & $1.98 \times 10^{20}$ & 0.251 & 1.3 \\
\hline PC5 & 0.510 & 0.313 & $3.45 \times 10^{19}$ & 0.160 & 3.4 & 0.485 & 0.298 & $3.05 \times 10^{19}$ & 0.158 & 3.6 \\
\hline
\end{tabular}
more random motion within the illuminated interfaces.

Table 3. Exponent s, Barrier energy Wm, Hopping frequency ( $\omega$ hopping), minimum hopping distance $\left(\mathrm{R}_{\min }\right)$ and density of state at Fermi level $\mathrm{N}\left(\mathrm{E}_{\mathrm{F}}\right)$ at high frequency 
Table 4. Exponent s (in Power law) at low and high frequencies, and Relaxation time- $\tau$, s

\begin{tabular}{|c|c|c|c|c|c|c|c|}
\hline \multicolumn{2}{|c|}{ mMole of Ter + BTh } & \multicolumn{3}{|l|}{ Dark } & \multicolumn{3}{|l|}{ Light } \\
\hline & & $\mathrm{s}($ Low $\omega)$ & s $($ High $\omega)$ & $\tau(\mathrm{s})$ & $s($ Low $\omega)$ & s $($ High $\omega)$ & $\tau(\mathrm{s})$ \\
\hline $0+10$ & $(\mathrm{PC} 1)$ & 2.029 & 0.750 & 0.639 & 1.260 & 0.731 & 0.252 \\
\hline $2.5+7.5$ & (PC2) & 0.942 & 0.287 & 0.503 & 1.978 & 0.263 & 0.798 \\
\hline $5.0+5.0$ & (PC3) & 1.089 & 0.359 & 0.798 & 1.167 & 0.336 & 0.399 \\
\hline $7.5+2.5$ & (PC4) & 1.296 & 1.005 & 0.399 & 1.326 & 0.843 & 0.252 \\
\hline $10+0$ & (PC5) & 1.296 & 0.510 & 2.00 & 1.326 & 0.485 & 0.503 \\
\hline
\end{tabular}

Table 4 lists data about $\mathrm{s}$ in low and high frequency region. It can be noticed that, $\mathrm{s}$ at high frequency, $\mathrm{s}$ is much smaller than that at low frequency. At low frequencies $s$ is $>1$. This also was observed in previous works (Chen et al 2002, Papathanassiou 2005). Furthermore, in most cases, illumination decreases the value of $\mathrm{s}$ in all frequency ranges, consequently increasing the value of $\mathrm{W}_{\mathrm{m}}$.

The values listed in Table 4 for $s>1$ indicate a limitation of power law application in low frequencies. Because the power law is an empirical formula that describes the responses of random mixtures of conductors and capacitors (Almond et al 2004), it is hard to derive an accurate physical meaning for $\mathrm{W}_{\mathrm{m}}$, corresponding to $\mathrm{s}>1$. Previous studies (Tsonos, 2018) discussed the cases when s values in the range $1 \leq \mathrm{s} \leq 2$, for a relatively narrow frequency range. This study attributed $s$ values greater than 1 to an additional molecular dipolar relaxation contribution at higher frequencies, and the existence of a well-defined minimum between DC conductivity contribution and a molecular dipolar dispersion. Theoretically, the prediction of $\mathrm{s}>1$ was based on assumption of an ideal network of conduction paths of various lengths (Papathanassiou et al 2007). The obtained results may indicate that the dipolar polarization processes of mixed phase polymers, used in this study, can coexist and be active along with the mobility of the charge carrier.

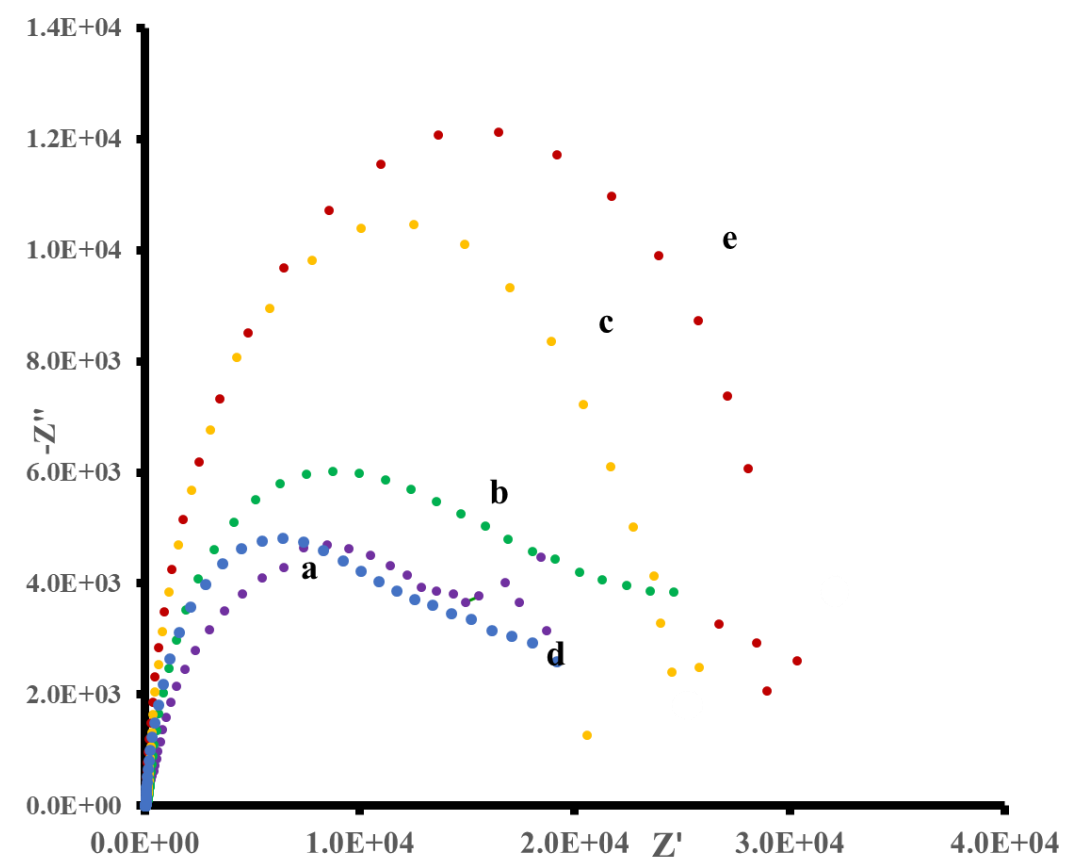

Figure 9. Nyquest plot at $-0.50 \mathrm{~V}$ vs $\mathrm{Ag} / \mathrm{AgCl}$ in phosphate electrolyte $(\mathrm{pH}=7.6)$ under illumination for: a) $\mathrm{PC}$, b) $\mathrm{PC} 2$, c) PC3, d) PC4, and e) PC5 

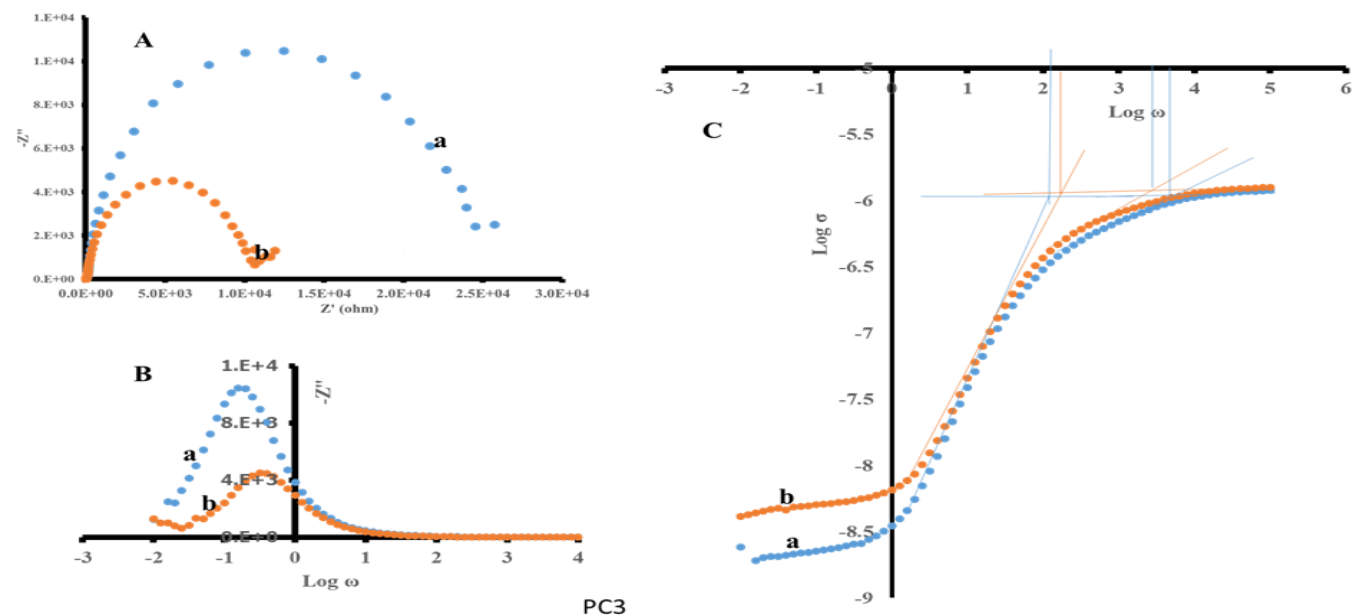

Figure 10. EIS Studies for PC3 in phosphate electrolyte ( $\mathrm{pH}=7.6)$ at $-0.50 \mathrm{~V}$ vs $\mathrm{Ag} / \mathrm{AgCl}$ : A) Nyquest Plot, B) Bode's plot, and C) $\log \omega$ vs $\log \sigma$ (conductivity): a) In thedark, b) Under illumination

\section{Conclusion}

The electro-polymerization of mixed monomers containing bi-thiophene (Bth) and ter-thiophene (Terth), resulted in the formation of intermixed phases. The lack of a systematic increase or decrease the studied properties with the decrease of Bth content in the monomer mixtures suggests that, each monomer mixture generates different phases with inconsistent structures. Optical, PEC, and EIS results do not support any monotonic relationship with monomer concentration. This can be attributed to the existence of partial alignment of the molecular chains formed during the oligomer polymerization processes. These partial alignments fold together and form different ordered regions.

\section{References}

Almond, D. P., \& Bowen, C. R. (2004). Anomalous Power Law Dispersions in ac Conductivity and Permittivity Shown to be Characteristics of Microstructural Electical Networks. Phys. Rev. Lett., 92, 157601. https://doi.org/10.1103/PhysRevLett.92.157601

Bard, A. J. (1979). Photoelectrochemistry and heterogeneous photocatalytic at semiconductor electrodes. $J$. Photochemistry, 10, 59. https://doi.org/10.1016/0047-2670(79)80037-4

Brennan, L. J., Purcell-Milton, F., Salmeron, A. S., Zhang, H., Govorov, A. O., Fedorov, A. V., \& Gun'ko, Y. K. (2015). Hot plasmonic electrons for generation of enhanced photocurrent in gold- $\mathrm{TiO}_{2}$ nanocomposites. Nanoscale Research Letters, 38. https://doi.org/10.1186/s11671-014-0710-5

Causa, M., De Jonghe-Risse, J., Scarongel, M., Brauer, J. C., Buchaca-Domingo, E., Moser, J. E, Stingelin, N., \& Banerji, N. (2016). The fate of electron-hole pairs in polymer:fullerene blends for organic photovoltaics. Nature communication. https://doi.org/10.1038/ncomms12556

Chen, R. H., Chang, R. Y., \& Shern, S. C. (2002). Dielectric and AC ionic conductivity investigation in $\mathrm{K}_{3} \mathrm{H}\left(\mathrm{SeO}_{4}\right)_{2}$ single crystal. J. Phys. \& Chem. of Solids, 63, 2069-2077. https://doi.org/10.1016/S0022-3697(02)00196-8

De Leon, A. C., Imperial, R. E. S., Chen, Q., \& Advincula, R. C. (2019) .One-Step Fabrication of Superhydrophobic/Superoleophilic Electrodeposited Polythiophene for Oil and Water Separation. Macromol. Mater. Eng., 1800722. https://doi.org/10.1002/mame.201800722

Drude, P. (1900). Zur Elektronentheorie der Metalle. Annalen der Physik. 306(3), 566. https://doi.org/10.1002/andp.19003060312

Funke, K. (1993). Jump relaxation in solid electrolytes. Prog. Sol. State Chem, 22, 111. https://doi.org/10.1016/0079-6786(93)90002-9

Garrett, C. G. R., \& Braittain, W. H. (1955). Physical theory of semiconductors surfaces. Physics review II, 99, 376. https://doi.org/10.1103/PhysRev.99.376

Holmes, P. J. (1961). The electrochemistry of semiconductors, Academic press, NY, 1961

Jonscher, A. K. (1977). The 'universal' dielectric response. Nature, 267, 673. https://doi.org/10.1038/267673a0

Joshia, J. H., Kanchan, D. K., Joshi, M. J., \& Jethva, H. O. (2017). Dielectric relaxation, complex impedance and 
modulus spectroscopic studies of mix phase rod like cobalt sulfide nanoparticles. Materials Research Bulletin, 93, 63. https://doi.org/10.1016/j.materresbull.2017.04.013

Kasem, K., Elmasry, M., Baker, K., \& Santucci, C. (2017). Photoelectrochemical and magnetic studies on photoactive interface thin film assemblies of poly bithiophene/poly 3-(2-thienyl) aniline/ferromagnetic $\mathrm{Mg}$-doped $\mathrm{Fe} 2 \mathrm{O} 3$ in aqueous electrolytes. Thin Solid Films, 634, 56. https://doi.org/10.1016/j.tsf.2017.05.016

Kasem, K., Sadou, H., \& Jeffers, A. W (2018). Optical, Photoelectrochemical and Impedance Studies on Poly 3,3' Dibromo, 2,2' Bithiophene: Effect of Bromine as a Substituent at C-3 Position in 2,2' Bithiophene Molecules. International Journal of Chemistry; 10(4). https://doi.org/10.5539/ijc.v10n4p83

Kasem, K., Worley, H., \& Elmasry, M. (2018). Optical and photoelectrochemical studies on photoactive inorganic/organic/organic/interface assemblies of CdS/poly 3-(2-thienyl) aniline/poly 2,2 bithiophene, Advanced Composites and Hybrid Materials. https://doi.org/10.1007/s42114-018-0055-0

Kolodziejczyk, B., David, M., \& Winther-Jensena, B. (2013). Enhanced absorption spectra of conducting polymers co-polymerised from thiophene derivatives. RSC Advances, 3(14), 4568. https://doi.org/10.1039/c3ra23120h

Kolodziejczyk, B., Winther-Jensen, O., Ng, C. H., Lin, S. H., Bao, Q. L., \& Winther-Jensen, B. (2014). Growth of polythiophene nano-walls and their unique electrochemical and optical properties.Mater. Horiz., 1, 452. https://doi.org/10.1039/c4mh00016a

Marcos, J., Santos, L., Emerson, M., Girotto, A., \& Nogueira, F. (2006). Photoelec-trochemical properties of poly(terthiophene) films modified with a fullerene derivative, Thin Solid Films, 515, 2644. https://doi.org/10.1016/j.tsf.2006.04.021

Mohammed, O. F. (2008). Direct femtosecond observation of tight and loose ionpairs upon photoinduced bimolecular electron transfer. Angew. Chem. Int. Ed., 47, 9044. https://doi.org/10.1002/anie.200803164

Oyama N. (1989). Chemical Sensor Technology, (Edited by T. Seiyama), 2, 99, Elsevier, Amsterdam. https://doi.org/10.1016/B978-0-444-98784-6.50012-X

Papathanassiou, A. N. (2005). On the power-law behavior of the AC conductivity of the mixed crystal $\left(\mathrm{NH}_{4}\right)_{3} \mathrm{H}\left(\mathrm{SO}_{4}\right)_{1.42}\left(\mathrm{SeO}_{4}\right)_{0.58}$. J. Phys. and Chemi of Solids, 66, 1849. https://doi.org/10.1016/j.jpcs.2005.06.003

Papathanassiou, A. N., \& Grammatikakis, S. J. (2007). Universal frequency-dependent ac conductivity of conducting polymer networks. Applied Physics Letters, 91, 122911. https://doi.org/10.1063/1.2779255

Reemts, J., \& Kittel, A. (2007). Persistent photoconductivity in highly porous ZnO films. J. Appl. Phys., 101. https://doi.org/10.1063/1.2407264

Sabari, G., \& Dhanushkodi, T. C. (2009). Cryst. Res. Tech., 44(12), 1297. https://doi.org/10.1002/crat.200900351.

Sharma P., \& Katyal S.C.(2007). Determination of optical parameters of $a$ - $\left(\mathrm{As}_{2} \mathrm{Se}_{3}\right)_{90} \mathrm{Ge}_{10}$ thin film..J. Physics $D$ : Applied Physics, 40(7), 2115. https://doi.org/10.1088/0022-3727/40/7/038

Spadavecchia, F., Ardizzone, S., Cappelletti, G., Falciola, L., Ceotto, M., \& Lotti, D. (2013). Investigation and optimization of photocurrent transient measurements on nano- $\mathrm{TiO}_{2}$. J. Appl. Electrochem., 43, 217. https://doi.org/10.1007/s10800-012-0485-2

Tauc, J. (1968). Optical properties and electronic structure of amorphous Ge and Si. Mater. Res Bulletin, 3(1968), 37. https://doi.org/10.1016/0025-5408(68)90023-8

Tsonos, C. (2018). Comments on frequency dependent ac conductivity in polymeric materials at low frequencies regime, arXiv.org, e-Print Archive. Condensed Matter, 1-13.

Urbach, F. (1953). The Long-Wavelength Edge of Photographic Sensitivity and of the Electronic Absorption of Solids. Phys. Review, 92, 1324. https://doi.org/10.1103/PhysRev.92.1324

Wei, Y., Chan, C. C., Tian, J., Jang, G. W., \& Hsueh, K. F. (1991). Electrochemical Polymerization of Thiophenes in the Presence of Bithiophene or Terthiophene: Kinetics and Mechanism of the Polymerization. Chem. Mater., 3, 888. https://doi.org/10.1021/cm00017a026

\section{Copyrights}

Copyright for this article is retained by the author(s), with first publication rights granted to the journal.

This is an open-access article distributed under the terms and conditions of the Creative Commons Attribution license (http://creativecommons.org/licenses/by/4.0/). 